\title{
Митохондриальные кардиомиопатии
}

\author{
И.В. Леонтьева, Е.А. Николаева \\ ОСП «Научно-исследовательский клинический институт педиатрии им. Ю.Е. Вельтищева» ГБОУ ВПО РНИМУ \\ им. Н.И. Пирогова, Москва
}

\section{Mitochondrial cardiomyopathies}

\author{
I.V. Leontyeva, E.A. Nikolaeva
}

Academician Yu.E. Veltishchev Research Clinical Institute of Pediatrics, N.I. Pirogov Russian National Research Medical University, Moscow

Рассмотрена проблема диагностики гетерогенных форм митохондриальных кардиомиопатий, связанных с нарушением окислительного фосфорилирования и снижением активности митохондриальной электронно-транспортной системы вследствие мутации генов митохондриальной или ядерной ДНК. Подчеркнуто, что митохондриальные кардиомиопатии редко представляют изолированное поражение миокарда, чаще служат проявлением мультисистемного заболевания. Дана характеристика кардиомиопатии при отдельных митохондриальных синдромах, отражены возможности лечения патологии.

Ключевые слова: дети, кардиомиопатия, митохондриальное заболевание, синдромы Кернса-Сейра, MELAS, MERRF, NARP, Барта, Ли, убидекаренон, сукцинаты, цитохром С, левокарнитин.

The paper considers the problem of diagnosing the heterogeneous forms of mitochondrial cardiomyopathies associated with impaired oxidative phosphorylation and decreased activity of the mitochondrial electron transport system due to mutations in mitochondrial or nuclear DNA genes. It is emphasized that mitochondrial cardiomyopathies rarely present as an isolated myocardial lesion and more frequently serve as a manifestation of multisystem disease. The paper provides the characteristics of cardiomyopathies in some mitochondrial syndromes and shows the possibilities of treating this disease.

Key words: children, cardiomyopathy, mitochondrial disease, Kearns-Sayre syndrome, MELAS syndrome, MERRF syndrome, NARP syndrome, Barth syndrome, Leigh syndrome, ubidecarenone, succinates, cytochrome C, levocarnitine.

$\mathbf{K}$ ардиомиопатии - гетерогенная группа заболеваний, характеризующихся выраженной структурной перестройкой миокарда, злокачественным течением, резистентностью к терапии, высокой смертностью вследствие нарастающей или возникающей внезапно при развитии жизнеугрожающих сердечных аритмий, сердечной недостаточности. В большинстве случаев диагностика кардиомиопатий основывается на клинических симптомах и данных функционального обследования, в первую очередь эхокардиографии, при этом истинная этиология заболевания часто не устанавливается $[1,2]$.

Основными причинами кардиомиопатий являются генетические факторы (в том числе мутации генов саркомерного комплекса, наследственные нарушения обмена веществ), воспалительные изменения в миокарде (при дилатационной кардиомиопатии) [1, 3, 4]. На основании современных экспериментальных и клинических исследований была выделена группа кардиомиопатий, связанных с нарушением окислительного фосфорилирования и снижением активно-

() Коллектив авторов, 2016

Ros Vestn Perinatol Pediat 2016; 3:22-30

DOI: $10.21508 / 1027-4065-2016-61-3-22-30$

Адрес для корреспонденции: Леонтьева Ирина Викторовна - д.м.н., проф., гл. н. сотр. отдела детской кардиологии и аритмологии Научно-исследовательского клинического института педиатрии им. Ю.Е. Вельтищева. Николаева Екатерина Александровна - д.м.н., и.о. рук. отдела психоневрологии и наследственных заболеваний того же учреждения 125412 Москва, ул. Талдомская, д.2 сти митохондриальной электронно-транспортной системы вследствие мутации генов митохондриальной или ядерной ДНК. Возросший интерес к митохондриальным кардиомиопатиям обусловлен новыми возможностями в диагностике и лечении этой патологии. Митохондриальные кардиомиопатии могут быть определены как заболевания миокарда, ассоциированные со структурными, количественными и функциональными нарушениями митохондрий либо с комбинацией этих нарушений. Как правило, митохондриальные кардиомиопатии являются составной частью полиорганного заболевания, реже встречаются как изолированное поражение сердца [5-7].

Важным звеном патогенеза митоходриальных болезней служит клеточный энергетический дефицит $[8,9]$. Нервная и мышечная ткань наиболее чувствительна к условиям энергетического голода [10]. В связи с этим не случайно энцефалопатия, отставание в психоречевом и моторном развитии, судороги, мышечная гипотония и кардиомиопатия - основные признаки, встречающиеся при митохондриальной патологии.

Генетические аспекты. Митохондриальные кардиомиопатии можно разделить на две большие группы: возникающие вследствие мутаций митохондриальной и ядерной ДНК.

Митохондриальные кардиомиопатии, обусловленные мутациями митохондриальной ДНК. Митохондриальная ДНК представляет собой особую структуру внеядерной ДНК, содержит 37 генов, кодирующих 
субъединицы I, III-V комплексов дыхательной цепи, транспортные и рибосомальные РНК. Мутации митохондриальной ДНК ведут к расстройству работы системы электронно-транспортной цепи и окислительного фосфорилирования, нарушению митохондриального синтеза белка. Дефекты митохондриальной ДНК обычно представлены крупными делециями, нередко сочетающимися с дупликациями (в родословных встречаются спорадически и не наследуются), и точковыми мутациями. Последние наследуются с высоким риском, строго по материнской линии (митохондриальное, материнское, или цитоплазматическое наследование). Это связано с тем, что именно материнская яйцеклетка служит источником митохондрий для организма ребенка. При оценке клинической значимости мутаций митоходриальной ДНК следует учитывать эффекты гомои гетероплазмии (соотношение мутантной и нормальной ДНК в клетке/ткани), а также возможное изменение уровня гетероплазмии в течение жизни. Различные варианты распределения мутантной митохондриальной ДНК в тканях плода существенно затрудняют определение медико-генетического прогноза у потомства женщин-носителей митохондриальных мутаций [11].

C митохондриальными кардиомиопатиями acсоциированы точковые мутации митохондриальных генов транспортных PHK - MTTL1 (3243A>G, $3260 \mathrm{~A}>\mathrm{G}, \quad 3303 \mathrm{C}>\mathrm{T}), \quad \operatorname{MTTK}(8344 \mathrm{~A}>\mathrm{G}, \quad 8348 \mathrm{~A}>\mathrm{G}$, $8363 \mathrm{~A}>\mathrm{G}), \quad$ MTTI $(4269 \mathrm{~A}>\mathrm{G}, \quad 4295 \mathrm{~A}>\mathrm{G}, \quad 4300 \mathrm{~A}>\mathrm{G}$, 4317A $>\mathrm{G}, \quad 4320 \mathrm{C}>\mathrm{T}), \quad M T T G \quad(9997 \mathrm{~T}>\mathrm{C}), \quad$ MTTL2 $(12297 \mathrm{~T}>\mathrm{C}), \operatorname{MTTT}(15923 \mathrm{~A}>\mathrm{G})$, а также мутации митохондриальных генов белков дыхательной цепи MTATP6 (8528T>C), МТATP8 (8993Т >C), мутации гена цитохрома b $M T C Y B(14849 \mathrm{~T}>\mathrm{C}, 15498 \mathrm{G}>\mathrm{A})$ [6]. Сочетание матерински наследуемой миопатии и кардиомиопатии (акроним MIMYCA - Maternally Inherited, Myopathy, Cardiomyopathy) возникает при мутациях $3260 \mathrm{~A}>\mathrm{G}$ и 3303C > T гена MTTL1. Делеции митохондриальной ДНК являются причиной нескольких митохондриальных синдромов, из них кардиомиопатия встречается при синдромах Кернса-Сейра и хронической наружной офтальмоплегии [5, 6, 12, 13].

Митохондриальные кардиомиопатии, обусловленные мутациями ядерной ДНК. Роль мутаций ядерных генов в происхождении митохондриальных кардиомиопатий стала очевидной в последнее десятилетие. Ядерные гены кодируют большинство полипептидов электронно-транспортной цепи (гены $N D U F S 2, N D U F V 2$ и др.), контролируют факторы сборки и функционирования дыхательных комплексов на митохондриальной мембране (SURF1, SCO1, SCO2, COX10, COX15 и др.), обеспечивают биогенез митохондрий, кодируют рибосомальные белки (MRPS22, MRPS16) и ферменты биосинтеза коэнзима $\mathrm{Q}_{10}(C O Q 9)$, контролируют факторы стабильности и репликации митохондриальной ДНК (POLG1,
ANT1, PEO1, TK2), состояние внутренней мембраны митохондрий (TAZ) [14-21]. Дефекты ядерных генов, обеспечивающих репликацию и функционирование митохондриальной ДНК, ведут к ее множественным делециям или деплеции (истощению), что подчеркивает главенствующую роль ядерного генома над митохондриальным [13, 22].

K настоящему времени показано, что мутации около 30 генов ядерной ДНК могут быть причиной развития митохондриальной кардиомиопатии - изолированной (реже) или в структуре полисистемного заболевания [23]. Перечень таких генов неуклонно увеличивается. В большинстве случаев митохондриальная кардиомиопатия характеризуется ранним дебютом [24], сочетается с энцефаломиопатией (задержка развития, мышечная гипотония/дистония, судороги), реже - с тубулярными расстройствами, поражением печени. В таблице представлены группы митохондриальных заболеваний с рано манифестирующей кардиомиопатией (в том числе у новорожденных). Основные проявления, как правило, не отличаются специфичностью, что затрудняет клиническую диагностику, требует дифференцирования с достаточно большим количеством гетерогенных заболеваний, и для генетического подтверждения диагноза приходится использовать панели генов или прибегать к экзомному секвенированию.

В то же время при ряде нозологических форм отмечается характерная симптоматика, дающая возможность установления диагноза на основании клинических данных и его подтверждения после молекулярно-генетического исследования конкретного гена. Так, при синдроме Сенгерса (дефект гена $A G K$ ) гипертрофическая кардиомиопатия сочетается с миопатическим синдромом, низкой переносимостью физической нагрузки, врожденной катарактой и лактат-ацидозом [19]. Гипертрофическая кардиомиопатия может трансформироваться в дилатационную с развитием сердечной недостаточности [20]. При дополнительном обследовании выявляют деплецию митохондриальной ДНК, феномен RRF («рваные» красные волокна) в мышечной ткани.

При сцепленном с хромосомой Х синдроме Барта (дефект гена $T A Z$ ) наблюдается характерное сочетание рано манифестирующей (с первых недель/ месяцев жизни, иногда пренатально) кардиомиопатии (чаще дилатационной, реже гипертрофической) с задержкой физического развития, миопатическим синдромом, нейтропенией. В половине случаев регистрируется высокая почечная экскреция 3-метилглутаконовой кислоты, отражающая вовлечение в патологический процесс внутренней митохондриальной мембраны $[25,26]$.

В более старшем возрасте появляются первые признаки атаксии Фридрейха (мутации гена FXN). Обструктивная гипертрофическая кардиомиопатия является важной составляющей этого заболевания 
и во многом определяет его прогноз [27, 28]. Кроме того, поздней манифестацией у подростков или взрослых характеризуются дилатационные кардиомиопатии, сочетающиеся с атаксией и депрессивными состояниями (мутации гена $P O L G 1)$ или с прогрессирующей наружной офтальмоплегией (мутации генов ANT1, Twinkle, POLG2). Наследование указанных заболеваний подчиняется классическим законам Менделя.

Согласно имеющимся данным, при поиске мутаций только в митотохондриальной ДНК диагноз митохондриальной болезни верифицируется почти у 50\% взрослых пациентов и только у 10-20\% детей $[5,6]$. Это отражает распространенность ядернои митохондриально-кодируемых митохондриальных заболеваний у больных разного возраста.

Другие варианты поражения сердца. Кроме кардиомиопатии, при митохондриальных заболеваниях нередко диагностируют изменения в проводящей системе сердца [29, 30], представленные фибрилляцией предсердий, атриовентрикулярной блокадой, синдромом Вольфа-Паркинсона-Уайта, блокадой проведения по пучку Гиса. Широкий спектр нарушений может быть объяснен с позиций дисфункции автономной нервной системы, выявляемой у большинства пациентов. Так, в исследовании R. Di Leo показано, что в $80 \%$ случаев у больных с митохондриальной патологией выявляются признаки автономной дисфункции, при этом в 46\% случаев отмечают выраженную автономную дисфункцию, в 36\% - умеренную; у больных установлено достоверное снижение уровня адреналина при переходе в ортоположение [30 ].

У пациентов с митохондриальными кардиомиопатиями также встречаются нарушения процесса реполяризации в виде $S T-T$ изменений [31]. Варианты поражения сердечно-сосудистой системы при классических митохондриальных синдромах характеризуются широким клиническим полиморфизмом.

Синдром Кернса-Сейра возникает в случае наличия спорадической делеции миохондриальной ДНК, у 90\% пациентов выявляется делеция, размер которой варьирует от 1,3 до 8,8 кб, реже возможна дупли- кация [12]. Заболевание характеризуется классической триадой: дебют в возрасте до 20 лет, пигментная ретинопатия, офтальмопарез (птоз) [32].

Варианты и степень выраженности поражения сердца в большинстве случаев определяют тяжесть течения и прогноз синдрома Кернса-Сейра. Изменения со стороны сердечно-сосудистой системы, как правило, проявляются нарушениями в проводящей системе. На ЭКГ выявляют удлинение интервала $P-R$, атриовентрикулярную блокаду 2-3-й степени, дистальную блокаду проведения по пучку Гиса [33, 34]. Длительное время поражение сердца может оставаться нераспознанным. Иногда серьезное внимание врачи обращают на состояние больных только при формировании полной атриовентрикулярной блокады, приводящей к резкой брадикардии, длительным паузам сердечного ритма с синкопальными состояниями приступами Морганьи-Адамса-Стокса. Следует подчеркнуть, что развитие полной атриовентрикулярной блокады может происходить внезапно и непредсказуемо (у 20\% пациентов) [35], что увеличивает риск внезапной смерти и требует экстренной имплантации электрокардиостимулятора. Полная атриовентрикулярная блокада приводит к миокардиальной дисфункции с последующим возможным развитием недостаточности кровообращения [36]. Высокий риск миокардиальной недостаточности на фоне полного атриовентрикулярного блока диктует необходимость имплантации пейсмекера типа DDD в ранние сроки, до появления жизнеугрожающих нарушений в проводящей системе сердца $[37,38]$.

Изменения в проводящей системы не всегда манифестируют полным атриовентрикулярным блоком. В ряде случаев происходит постепенное нарастание нарушений, начинающихся с дистальной блокады правой и/или передней ветви левой ножки пучка Гиса $[33,34]$. Вместе с тем следует учитывать, что у ряда пациентов возможно возникновение мономорфной желудочковой тахикардии или тахикардии по типу torsade de pointes [39]. В такой ситуации для профилактики внезапной сердечной смерти следует отдавать предпо-

Таблица. Группы ядерно-кодируемых митохондриальных заболеваний, характеризующихся ранней манифестацией и кардиомиопатией

\begin{tabular}{|c|c|c|}
\hline Клинический фенотип & Тип наследования & Ген \\
\hline $\begin{array}{l}\text { Митохондриальная энцефаломиопатия с кардио- } \\
\text { миопатией, }\end{array}$ & Аутосомно-рецессивный & $\begin{array}{l}\text { NDUFS2, NDUFAF1, NDUFA11, } \\
\text { ACAD9, SDHA, SDHB, SDHC, } \\
\text { SDHD, SCO2, ANT1, COX15, } \\
\text { AARS2, MRPL44, SLC } 25 A 3\end{array}$ \\
\hline в том числе синдром Сенгерса & & $A G K$ \\
\hline $\begin{array}{l}\text { Митохондриальная энцефаломиопатия с кардио- } \\
\text { миопатией и тубулопатией }\end{array}$ & Аутосомно-рецессивный & $\begin{array}{l}\text { MRPS22 (C3ORF5), MRPS16, } \\
\text { COQ9 }\end{array}$ \\
\hline $\begin{array}{l}\text { Митохондриальная энцефаломиопатия с кардио- } \\
\text { миопатией и 3-метилглутаконовой ацидурией, }\end{array}$ & Аутосомно-рецессивный & $\begin{array}{l}\text { TMEM70, ATP5E, ATPAF2, } \\
\text { DNAJC19 }\end{array}$ \\
\hline в том числе синдром Барта & X-сцепленный рецессивный & $T A Z$ \\
\hline
\end{tabular}


чтение кардиовертеру дефибриллятору по сравнению с электрокардиостимулятором [39]. Существует мнение, что имплантация кардиовертера дефибриллятора у пациентов с синдромом Кернса-Сейра позволяет контролировать не только периоды асистолии, но и фибрилляцию желудочков [6].

Реже при синдроме Кернса-Сейра развиваются миокардиальные нарушения по типу дилатационной кардиомиопатии [33, 34, 40]. Эти изменения связывают с дефицитом цитохром С-оксидазы, обусловленным дефектом митохондриальной ДНК в позиции 8482-13459 [40]. Дилатационная кардиомиопатия может сочетаться с признаками умеренной гипертрофии стенок левого желудочка. Как правило, развитию ремоделирования сердца предшествуют нарушения в проводящей системе [40, 41]. Дилатация полости левого желудочка сопровождается выраженными нарушениями систолической функции (диффузный гипокинез стенок левого желудочка, уменьшение фракции укорочения левого желудочка и скорости циркулярного сокращения волокон), в дальнейшем присоединяется диастолическая дисфункция (снижение соотношения скорости трансмитральных потоков Е/А, увеличение времени децеллерации и предызгнания), что ухудшает прогноз заболевания [34, 40, 41].

Под нашим наблюдением находились 7 пациентов с синдромом Кернса-Сейра. Наиболее тяжелое поражение сердца было выявлено у девочки 14 лет. Было отмечено диффузное прогрессирующее поражение проводящей системы, начиная с дистальной двухпучковой блокады ножек пучка Гиса и транзиторной атриовентрикулярной блокады 1-й степени с последующим развитием полной блокады левой ножки пучка Гиса, полной атриовентрикулярной блокады, возникновением приступов МорганьиАдамса-Стокса, что потребовало экстренной имплантации электрокардиостимулятора. Указанные нарушения сопровождались развитием кардиомиопатии, сочетающей как дилатацию полости левого желудочка, так и симметричную гипертрофию левого желудочка без обструкции. Наблюдалось резкое снижение систолической функции в комбинации с обширными ишемическими изменениями в области переднебоковой стенки левого желудочка (деформация желудочкового комплекса по типу $Q S \mathrm{~V}_{1-5}$ ), что было расценено как косвенные свидетельства рубцовых изменений в миокарде [34 ].

Вместе с тем миокардиальные нарушения у больных с синдромом Кернса-Сейра могут длительно протекать субклинически. Для ранней диагностики целесообразно проведение магнитно-резонансной томографии, которая позволяет выявлять фиброзные/ рубцовые изменения в миокарде [42]. Возникновение миокардиальной дисфункции, снижение систолической функции и развитие тяжелой биветрикулярной сердечной недостаточности резко ухудшают прогноз и нередко приводят к летальному исходу.
G. Hübner и соавт. [43] сообщили о результатах аутопсии 26-летнего умершего пациента с синдромом Кернса-Сейра. Клинические проявления характеризовались сочетанием миопатии и дилатационной кардиомиопатии, осложненной рефрактерной сердечной недостаточностью, явившейся причиной смерти. Макроскопически была обнаружена выраженная дилатация левого желудочка. Гистологические данные выявили значительное уменьшение миофибрилл в комбинации с резко увеличенным количеством митохондрий с нарушенной структурой. Аномальные митохондрии локализовались как в кардимиоцитах, так и в волокнах проводящей системы сердца. Дилатационная кардиомиопатия и прогрессирующая сердечная недостаточность на фоне тяжелой систолической дисфункции являются показанием к трансплантации сердца [6].

Синдром Пирсона манифестирует у детей первых месяцев жизни, характеризуется сидеробластной анемией, экзокринной дисфункцией поджелудочной железы, нейтропенией и тромбоцитопенией. Большинство детей умирают на первом году жизни, трансфузии крови часто оказываются недостаточно эффективными. Синдром развивается при наличии делеции митохондриальной ДНК. Во многих случаях у выживших детей данный синдром с возрастом трансформируется в синдром Кернса-Сейра с характерными нарушениями в проводящей системе сердца и дилатацией левого желудочка с явлениями сердечной недостаточности [44].

Синдром MELAS (митохондриальная энцефаломиопатия, лактат-ацидоз, инсультоподобные эпизоды). Основными характеристиками заболевания являются инсультоподобные приступы, возникающие в возрасте до 40 лет (в том числе в детском возрасте), приступы мигренеподобной головной боли, снижение интеллекта по типу деменции, эпилепсия, проксимальная мышечная слабость, выраженные признаки митохондриальной дисфункции (феномен RRF) по данным мышечной биопсии [45]. Возраст дебюта заболевания вариабелен, наиболее часто от 6 до 10 лет. При компьютерной томографии головного мозга выявляются зоны инфарктов, преимущественно в области гемисфер, что и обусловливает неврологическую симптоматику [46].

В основе синдрома лежат точковые мутации митохондриальной ДНК, в $80 \%$ случаев встречается мутация 3243A>G гена MTTL1. Также установлены мутации в других генах митохондриальной ДНК(MTTL1, MT-ND1, MTND5, MT-COXIII) [47, 48]. Мутации присутствуют в скелетной и сердечной мышцах, печени, почках, поджелудочной железе, мозжечке, коре больших полушарий.

Изменения со стороны сердца возникают у $40 \%$ пациентов, чаще они проявляются концентрической (симметричной) гипертрофической кардиомиопатией, особенностью которой служит раннее развитие 
миокардиальной дисфункции в виде диффузного гипокинеза, с возможностью дальнейшей трансформации в дилатационную кардиомиопатию [49, 50]. Описаны варианты асимметричной гипертрофической кардиомиопатии с нормальной систолической функцией. Характерны нарушения сердечного ритма: предсердный ритм, суправентрикулярная экстрасистолия от единичной до аллоритмии по типу бигемении, синдром Вольфа-Паркинсона-Уайта [51]. Морфологические изменения в биоптате сердечной мышцы (эндомиокардиальная биопсия) характеризуются выраженным феноменом RRF, явлениями микроангиопатии, что способствует ишемическим изменениям в миокарде [52].

Под нашим наблюдением находились 2 пациента с синдромом MELAS. В первой семье старший ребенок умер в возрасте 10 лет (отмечались приступы рвоты, частые приступы мигренеподобной головной боли, выраженная мышечная слабость, утомляемость, косоглазие, атрофия зрительного нерва), у матери - частые приступы головной боли, непереносимость физических нагрузок.

Возраст дебюта заболевания в том и другом случае -8 лет. Начальными симптомами явились мигренеподобные приступы головной боли, сопровождавшиеся тошной и рвотой. Изменения неврологического статуса характеризовались мышечной слабостью, повышенной утомляемостью при физической нагрузке, изменением походки. Впоследствии развилась атаксия, нарушение речи, двустороннее снижение слуха, появились эпилептические приступы, вплоть до эпилептического статуса. В возрасте 11 и 12 лет соответственно у детей возник инсультоподобный эпизод и развился стойкий гемипарез.

В одном случае изменения со стороны сердца характеризовались симметричной гипертрофической кардиомиопатией (толщина задней стенки левого желудочка и межжелудочковой перегородки 11 мм, при норме 7 мм). Имели место нарушения ритма эктопический предсердный ритм, суправентрикулярная экстрасистолия по типу три- и квадригемении, нарушение процессов реполяризации. У другого пациента в возрасте 12 лет была выявлена дилатационная кардиомиопатия, с выраженным снижением контрактильной способности миокарда (рис. 1). По данным ЭКГ - резко выраженная синусовая тахикардия, синдром Вольфа-Паркинсона-Уайта (рис. 2). Нарушения метаболизма глюкозы и активности цикла Кребса в миокарде были установлены по данным позитронно-эмиссионной томографии (рис. 3). Метаболизм глюкозы оценивался по распределению фтордезоксиглюкозы, степень окисления жиров - по распределению 11С-ацетата [53].

Синдром MERRF (миоклонус-эпилепсия и «рваные» красные мышечные волокна). Заболевание чаще всего обусловлено точковой мутацией в позиции 8344(A $>\mathrm{G})$ митохондриального гена $M T T K$ транспортной РНК лизина [54]. Патогенез связан с нарушением синтеза белка, в первую очередь это касается субъединиц цитохромоксидазы. Возраст дебюта синдрома MERRF вариабелен - от 3 до 63 лет [6, 7]. Экстракардиальными симптомами, доминирующими в клинической картине, являются миоклонус-эпилепсия, атаксия, деменция, потеря слуха и мышечная слабость. При компьютерной томографии могут выявляться множественные церебральные инфаркты.

Изменения со стороны сердца сходны с таковыми при синдроме MELAS, могут проявляться как симметричной гипертрофической, так и дилатационной

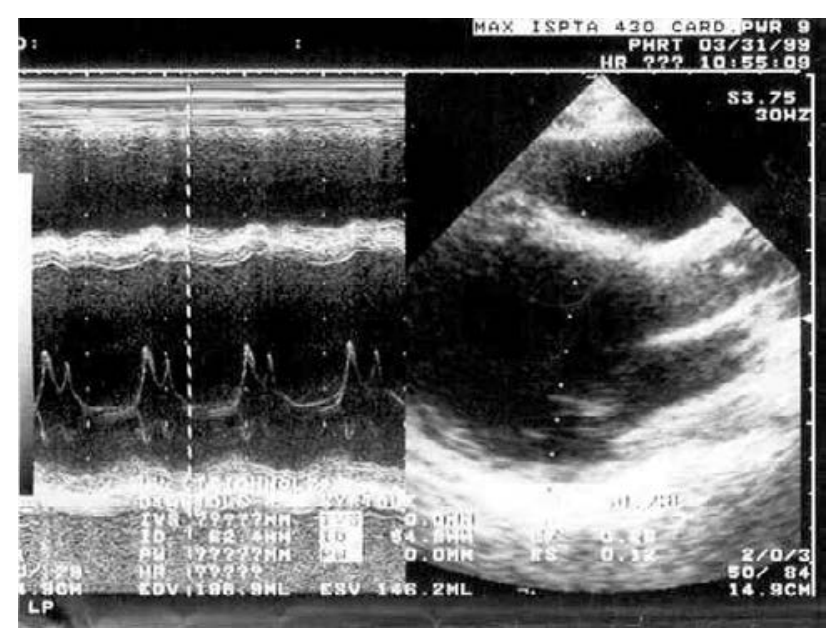

Puc. 1. Эхокардиограмма ребенка И. с синдромом MELAS. Выраженная дилатация полости левого желудочка (конечный диастолический диаметр левого желудочка 61 мм), снижение систолической функции (фракция выброса 0,32).

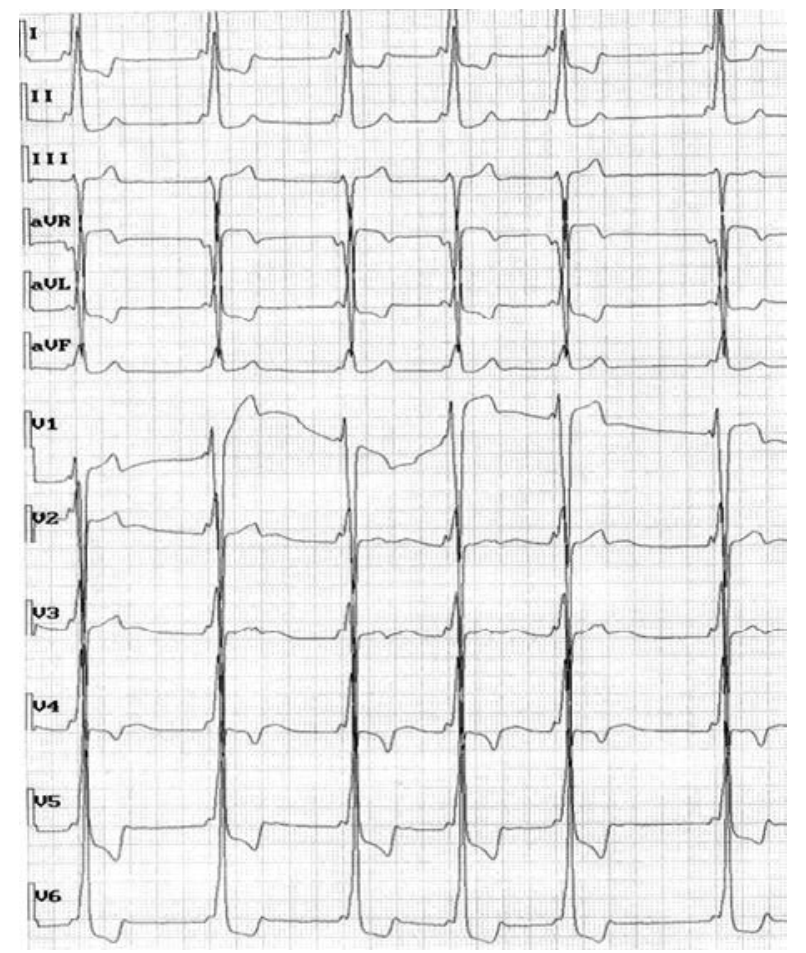

Puc. 2. ЭКГ больного И. (синдром MELAS): синдром Вольфа-Паркинсона-Уайта. 
кардиомиопатией. Гипертрофическая кардиомиопатия в большинстве случаев сочетается с выраженной миокардиальной систолической дисфункцией и быстро трансформируется в дилатационную с явлениями застойной сердечной недостаточности [55]. Характерны нарушения сердечного ритма и проводимости. Часто встречается синдром Вольфа-Паркинсона-Уайта, желудочковые тахиаритмии, что создает предпосылки для возникновения жизнеугрожающих состояний [56].

Под нашим наблюдением находился ребенок с синдромом MERRF. Изменения со стороны сердца характеризовались симметричной гипертрофической кардиомиопатией, синдромом Вольфа-Паркинсона-Уайта. В биоптатах скелетных мышц были обнаружены типичные RRF. Ферментно-гистохимический анализ выявил недостаточность цитохром С-оксидазы. При электронной микроскопии наблюдалось увеличение размеров митохондрий, их деформация, липидные включения [57].

Синдром NARP (нейропатия, атаксия, пигментный ретинит). Синдром обусловлен точковой мутацией в позиции 8993 (8993Т $>\mathrm{G}$ и 8993Т $>\mathrm{C})$ в митохондриальном гене MT-ATP6 [58]. Основные проявления заболевания: когнитивные нарушения (задержка психического развития), атаксия, полинейропатия, пигментная дегенерация сетчатки, гипертрофическая кардиомиопатия в сочетании с выраженной миокардиальной дисфункцией, снижением систолической функции, что приводит к сердечной недостаточности [59].

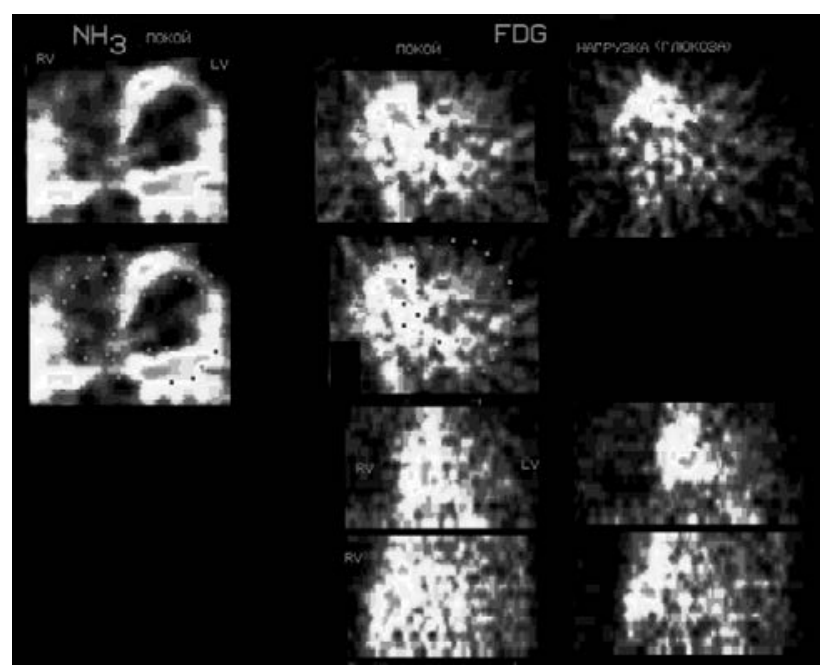

Рис. 3. Позитронно-эмиссионная томограмма больного И. (синдром MELAS). Визуализируются оба желудочка, увеличенные в размерах. На томограммах с 13NH3 выделяются стенки и полости желудочков, распределение препарата равномерное, накопление повышено $(K=4,5-6,4)$, что свидетельствует о нормальном кровоснабжении миокарда. Накопление фтордезоксиглюкозы стенками миокарда резко снижено, невозможно выделить стенки и полости левого желудочка $(\mathrm{K}=0,6-1,1)$. Реакция на нагрузку глюкозой отсутствует.
Энцефаломиопатия Ли. Заболевание является исключительно генетически гетерогенным. К этому патологическому фенотипу могут вести мутации как митохондриальной, так и ядерной ДНК, связанные с дефицитом комплексов дыхательной цепи, коэнзима $\mathrm{Q}_{10}$, пируватдегидрогеназного комплекса и др. Наиболее частой причиной энцефаломиопатии Ли служат гомозиготные или компаунд-гетерозиготные мутации гена $S U R F 1$, принадлежащего ядерной ДНК и обеспечивающего функционирование комплекса IV дыхательной цепи [60]. Клинический симптомокомплекс характеризуется манифестацией в раннем возрасте, нарушением психомоторного развития, мышечной дистонией, эпилепсией, атрофией зрительных нервов и др. На магнитно-резонансной томограмме головного мозга обнаруживают симметричное изменение МР-сигнала в проекции базальных ганглиев. Поражение сердца в виде гипертрофической или дилатационной кардиомиопатии наиболее часто встречается при формах заболевания, обусловленных дефицитом комплекса I дыхательной цепи [59, 61].

Биохимические критерии диагностики митохондриальной кардиомиопатии. Для диагностики митохондриальной дисфункции важное значение имеют биохимические показатели, такие как метаболический ацидоз, высокий уровень в крови лактата (более 2,2 ммоль/л) и пирувата (более 0,12 ммоль/л), изменение соотношения лактат/пируват (более 20), повышение активности лактатдегидрогеназы. У части больных может определяться умеренное повышение показателя креатинфосфониназы.

Значение гистохимического исследования мышечного биоптата для диагностики митохондриальной патологии. Проведение биопсии скелетной мышцы с гистохимическим анализом позволяет выявить морфологические маркеры митохондриальной дисфункции: увеличенное количество мышечных волокон типа RRF, субсарколеммальные скопления гликогена, липидов и кальция [57]. Согласно современным

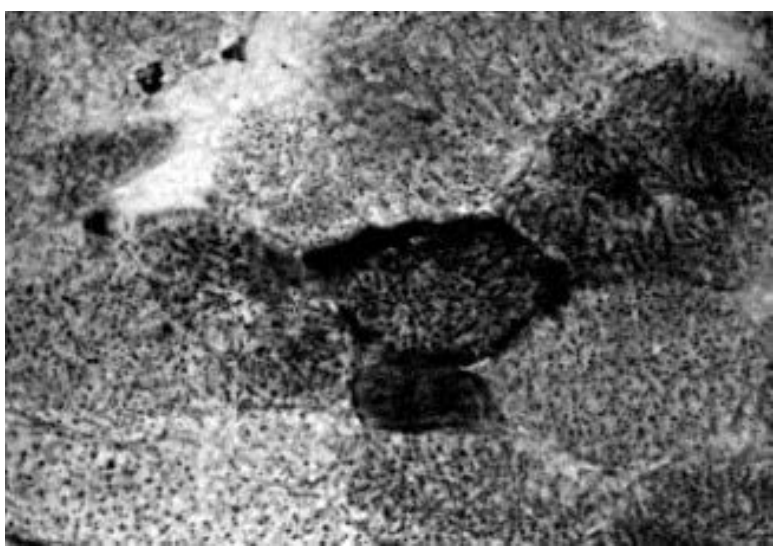

Puc. 4. Выраженный феномен RRF в биоптате скелетной мышцы (окраска на сукцинатдегидрогеназу) у ребенка 13 лет с синдромом MELAS. Ув. X 400. 
представлениям, наличие RRF является общепринятым маркером митохондриальной недостаточности (в норме их количество не превышает 5\%), однако этот морфологический признак встречается и при других состояниях, сопровождающихся митохондриальной дисфункцией, - при врожденных миопатиях другого происхождения, болезнях соединительной ткани и др. Более патогномоничным для митохондриальных болезней является снижение активности митохондриальных ферментов (сукцинатдегидрогеназы, цитохромоксидазы), выявляемое при гистохимическом анализе биоптатов. На рис. 4 изображен выраженный феномен RRF до $35 \%$ у пациента с синдромом MELAS. Электронная микроскопия выявляет аномалии структуры митохондрий (рис. 5).

Лечение митохондриальных заболеваний представляет очень трудную задачу, что обусловлено тяжестью нарушений митохондриальной энергетической функции и ее чрезвычайной значимостью для всего организма, отдельных органов и тканей. Стратегия лечения митохондриальных болезней заключается в повышении эффективности биологических процессов тканевого дыхания и окислительного фосфорилирования. Опыт многих клиницистов свидетельствует, что к настоящему моменту эффективное лечение митохондриальных болезней не разработано. В то же время для облегчения состояния пациентов, улучшения качества жизни назначается комплексная терапия. Основным компонентом комплекса лечения служит группа препаратов, стимулирующих перенос электронов в дыхательной цепи: коэнзим $\mathrm{Q}_{10}$ (убидекаренон), его аналог идебенон, сукцинаты, цитохром С. Дополнительно больным назначают витамины группы В (никотинамид, рибофлавин), витамины Е и С, карнитин и др. [62, 63].

K. Arakawa и соавт. [63] на основании диагностики нарушений метаболизма в цикле Кребса по данным позитронно-эмиссионной томографии предложил использовать L-аргинин для лечения кардиомиопатии у пациентов с синдромом MELAS.
Кроме того, лечение митохондриальных кардиомиопатий включает применение медикаментозных препаратов для коррекции проявлений сердечной недостаточности и антиаритмических средств. Ингибиторы ангиотензинпревращающего фермента и бета-адреноблокаторы успешно используют для коррекции миокардиальной дисфункции при гипертрофических кардиомиопатиях [64]. Высокий риск развития жизнеугрожающих ситуаций является показанием для применения инвазивных методов лечения, таких как имплантация электрокардиостимулятора или кардиовертера дефибриллятора, радиочастотная абляция [65]. При рефрактерной сердечной недостаточности на фоне применения медикаментозной терапии у пациентов с изолированной митохондриальной кардиомиопатией проводится трансплантация сердца [66].

\section{Заключение}

В отечественной детской кардиологической практике митохондриальные кардиомиопатии при жизни, как правило, остаются нераспознанными или диагностируются недостаточно достоверно. Для улучшения диагностики этой патологии большое внимание следует уделять данным семейного анамнеза, учитывая возможность материнского наследования. При подозрении на митохондриальный генез кардиомиопатии необходимо проведение комплексного обследования ребенка для установления полиорганного характера заболевания.

Особенностью поражения при митохондриальных капрдиомиопатиях является сочетание дилатации полостей сердца и гипертрофии миокарда (преимущественно задней стенки) с проявлениями фиброэластоза эндокарда, концентрический характер гипертрофической кардиомиопатии с быстрым развитием систолической дисфункции, высокая частота нарушений ритма (суправентрикулярная и желудочковая экстрасистолия, тахикардия) и проводимости (синдром слабости синусового узла, атриовентрикулярная
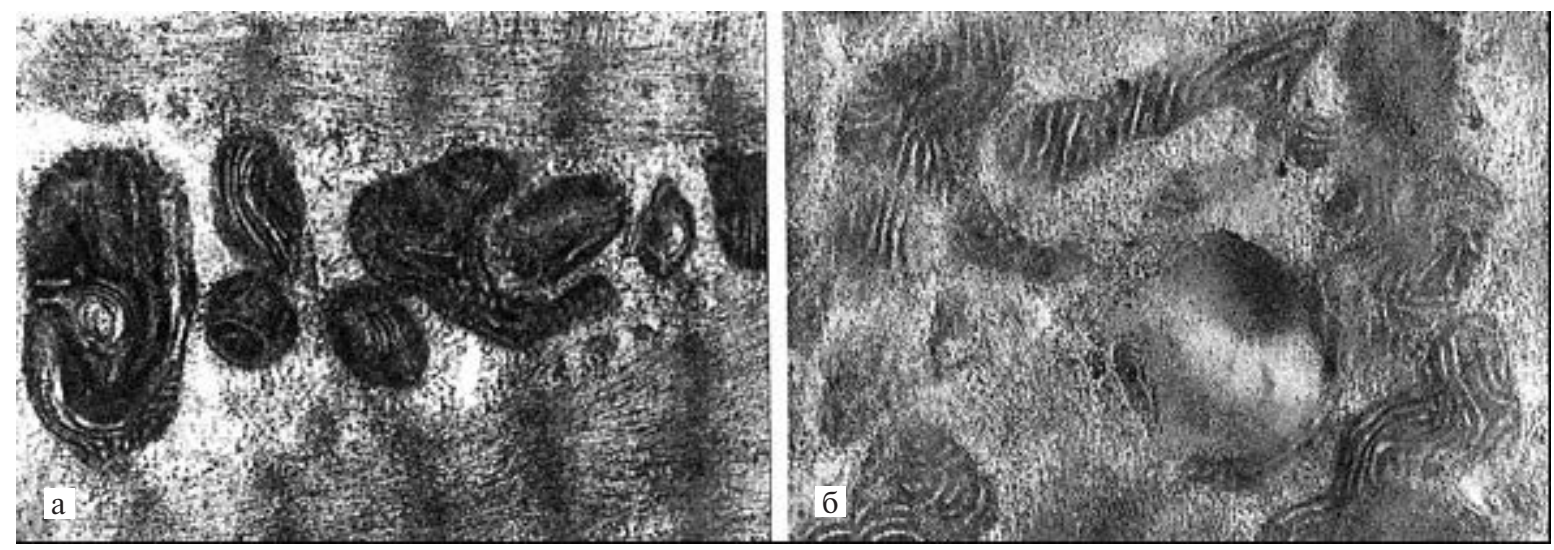

Рис. 5. Митохондрии различной формы и величины с дезориентированными (а) и частично слитыми кристами (б). Органеллы окружают липидное включение. Электронная микроскопия биоптата скелетной мышцы ребенка 7 лет с синдромом MELAS. X 2000. 
блокада, внутрижелулочковая блокада), синдром Вольфа-Паркинсона-Уайта.

План обследования ребенка с кардиомиопатией, предположительно митохондриального генеза, должен включать магнитно-резонансную томографию сердца, позитронно-эмиссионную томографию (по показаниям), электроэнцефалографию, электромиографию, консультации невропатолога, окулиста, генетика, биохимическое исследование крови с определением уровня лактата и пирувата на фоне стандартного глюкозотолерантного теста, определение почечной экскреции органических кислот, кислотно-щелочного состояния крови, биопсию скелетной мышцы (по показаниям) с морфологическим и гистохимическим исследованием, генетическое тестирование. Согласно современным представлениям, диагноз митохондриального заболевания не может считаться окончательно установленным без молекулярно-генетического подтверждения. Только верификация генетического дефекта дает возможность обеспечить эффективную медико-генетическую помощь семье больного ребенка.

\section{ЛИТЕРATУPA (REFERENCES)}

1. Wilkinson J.D., Landy D.C., Colan S.D. et al. The pediatric cardiomyopathy registry and heart failure: key results from the first 15 years. Heart Fail Clin 2010; 6: 401-441.

2. Byers S.L., Ficicioglu C. Infant with cardiomyopathy: When to suspect inborn errors of metabolism? World J Cardiol 2014; 6: 11: 1149-1155.

3. Cox G.F. Diagnostic approaches to pediatric cardiomyopathy of metabolic genetic etiologies and their relation to therapy. Prog Pediatr Cardiol 2007; 24: 15-25.

4. Elliott P., Andersson B., Arbustini E. et al. Classification of the cardiomyopathies: a position statement from the European Society Of Cardiology Working Group on Myocardial and Pericardial Diseases. Eur Heart J 2008; 29: 270-276.

5. Meyers D.E., Basha H.I., Koenig M.K. Mitochondrial cardiomyopathy: pathophysiology, diagnosis, and management. Tex Heart Inst J 2013; 40: 385-394.

6. Berardo A., Musumeci O., Toscano A. Cardiological manifestations of mitochondrial respiratory chain disorders. Acta Myologica 2011; XXX: 9-15.

7. Holmgren D., Wahlander H., Eriksson B.O. et al. Cardiomyopathy in children with mitochondrial disease: clinical course and cardiological findings. Eur Heart J 2003; 4: 280-288.

8. Kompare M., Rizzo W.B. Mitochondrial fatty-acid oxidation disorders. Semin Pediatr Neurol 2008; 15: 140-149.

9. Noji H., Yoshida M. The rotary machine of the cell, ATP synthase. J Biol Chem 2001; 276: 1665-1668.

10. Niizuma K., Endo H., Chan P.H. Oxidative stress and mitochondrial dysfunction as determinants of ischemic neuronal death and survival. J Neurochem 2009; 109: 133-138.

11. Mehrazin M., Shanske S., Kaufmann P. et al. Longitudinal changes of mtDNA A3243G mutation load and level of functioning in MELAS. Am J Med Genet 2009; 149: 584-587.

12. Zeviani M., Moraes C.T., DiMauro S. et al. Deletions of mitochondrial DNA in Kearns-Sayre syndrome. Neurology 1998; 51: $1525-1533$

13. Hudson G., Deschauer M., Taylor R.W. et al. POLG1, C10ORF2, and ANT1 mutations are uncommon in sporadic progressive external ophthalmoplegia with multiple mitochondrial DNA deletions. Neurology 2006; 66: 1439-1441.

14. López-Gallardo E., López-Pérez M.J., Montoya J. et al. CPEO and KSS differ in the percentage and location of the mtDNA deletion. Mitochondrion 2009; 9: 314-317.

15. Van Goethem G., Martin J.J., Van Broeckhoven C. Progressive external ophthalmoplegia and multiple mitochondrial DNA deletions. Acta Neurol Belg 2002; 102: 39-42.

16. Papa S., Petruzzella V., Scacco S. et al. Pathogenetic mechanisms in hereditary dysfunctions of complex I of the respiratory chain in neurological diseases. Biochim Biophys Acta 2009; 1787: 502-517.

17. Monnot S., Chabrol B., Cano A. et al. Cytochrome c oxydasedeficient Leigh syndrome with homozygous mutation in
SURF1 gene. Arch Pediatr 2005; 12: 568-571

18. Mobley B.C., Enns G.M., Wong L.J. et al. A novel homozygous SCO2 mutation, p.G193S, causing fatal infantile cardioencephalomyopathy. Clin Neuropathol 2009; 28: 143-149.

19. Jordens E.Z., Palmieri L., Huizing M. et al. Adenine nucleotide translocator 1 deficiency associated with Sengers syndrome. Ann Neurol 2002; 52: 95-99.

20. Palmieri L., Alberio S., Pisano I. et al. Complete loss-of-function of the heart/muscle-specific adenine nucleotide translocator is associated with mitochondrial myopathy and cardiomyopathy. Hum Mol Genet 2005; 14: 3079-3088.

21. Joost K., Rodenburg R., Piirsoo A. et al. A novel mutation in the $\mathrm{SCO} 2$ gene in a neonate with early-onset cardioencephalomyopathy. Pediatr Neurol 2010; 42: 227-230.

22. Zeviani $M$. The expanding spectrum of nuclear gene mutations in mitochondrial disorders. Semin Cell Dev Biol 2001; 12: $407-416$.

23. Николаева E.A. Диагностика и профилактика ядернокодируемых митохондриальных заболеваний у детей. Рос вестн перинатол и педиатр 2014; 59: 2: 19-28. (Nikolaeva E.A. Diagnostics and prevention of nuclear coded mitochondrial diseases at children. Ros vestn perinatol i pediatr 2014; 59: 2: 19-28.)

24. Colan S.D. Hypertrophic cardiomyopathy in childhood. Heart Fail Clin 2010; 6: 433-444.

25. Houtkooper R.H., Turkenburg M., Poll-The B.T. et al. The enigmaticrole of tafazzin in cardiolipin metabolism. Biochim Biophys Acta 2009; 1788: 2003.

26. Леонтьева И.В., Николаева Е.А. Поражение сердца при синдроме Барта. Рос вестн перинатол и педиатр 2016; 1: 26-32. (Leont'eva I.V., Nikolaeva E.A. Cardiac damage in Barth syndrome. Ros vestn perinatol i pediatr 2016; 1: 26-32.)

27. Pandolfo M., Pastore A. The pathogenesis of Friedreich ataxia and the structure and function of frataxin. J Neurol 2009; 256: 9-17.

28. Delatycki M.B. Evaluating the progression of Friedreich ataxia and its treatment. J Neurol 2009; 256: Suppl 1: 36-41.

29. Yaplito-Lee J., Weintraub R., Jamsen K. et al. Cardiac manifestations in oxidative phosphorylation disorders of childhood. J Pediatr 2007; 150: 407-411.

30. Di Leo R., Musumeci O., de Gregorio C. et al. Evidence of cardiovascular autonomic impairment in mitochondrial disorders. J Neurol 2007; 254: 1498-1503.

31. Scaglia F., Towbin J.A., Craigen W.J. et al. Clinical spectrum, morbidity, and mortality in 113 pediatric patients with mitochondrial disease. Pediatrics 2004; 114: 925-931.

32. Wabbels B., Ali N., Kunz W.S. et al. Chronic progressive external ophthalmoplegia and Kearns-Sayre syndrome: interdisciplinary diagnosis and therapy. Ophthalmology 2008; 105: 550-556.

33. Young T.J., Shah A.K., Lee M.H., Hayes D.L. Kearns-Sayre syndrome: a case report and review of cardiovascular complications. Pacing Clin Electrophysiol 2005; 28: 454-457. 
34. Леонтьева И.В., Николаева Е.А., Сухоруков В.С. Варианты поражения сердечно-сосудистой системы при синдроме Кернса-Сейра. Рос вестн перинатол и педиатр 1999; 6: 26-32. (Leont'eva I.V., Nikolaeva E.A., Suchorukov V.S. Variants of cardiovascular lesion in Kearns-Sayre syndrome. Рос вестн перинатол и педиатр 1999; 6: 26-32.)

35. Charles R., Holt S., Kay J.M. et al. Myocardial ultrastructure and the development of atrioventricular block in KearnsSayre syndrome. Circulation 1981; 63: 214-219.

36. Fromenty B., Carrozzo R., Shanske S., Schon E.A. High proportions of mtDNA duplications in patients with KearnsSayre syndrome occur in the heart. Am J Med Genet 1997; 71: 4: 443-452.

37. Kakura H., Tachibana Y., Nakamura K. et al. Mitochondrial encephalomyopathy (Kearns-Sayre syndrome) with complete atrioventricular block: a case report. Jpn Circ J 1998; 62: 8: 623-625.

38. Lewy P., Leroy G., Haiat R. et al. Kearns-Sayre syndrome. A rare indication for prophylactic cardiac pacing. Arch Mal Coeur Vaiss 1997; 90: 1: 93-97.

39. Subbiah R.N., Kuchar D., Baron D. Torsades de pointes in a patient with Kearns-Sayre syndrome: a fortunate finding. Pacing Clin Electrophysiol 2007; 30: 137-139.

40. Consalvo D., Villegas F., Villa A. Severe cardiac failure in Kearns-Sayre syndrome. Medicina (B Aires) 1997; 57: 1: 67-71.

41. Akaike M., Kawai H., Yokoi K. Cardiac dysfunction in patients with chronic progressive external ophthalmoplegia. Clin Cardiol 1997; 20: 3: 239-243.

42. Kabunga P., Lau A.K., Phan K. et al. Systematic review of cardiac electrical disease in Kearns-Sayre syndrome and mitochondrial cytopathy. Int J Cardiol 2015; 181: 303-310.

43. Hübner G., Gokel J.M., Pongratz D. et al. Fatal mitochondrial cardiomyopathy in Kearns-Sayre syndrome. Virchows Arch A Pathol Anat Histopathol 1986; 408: 6: 611-621.

44. Krauch G., Wilichowski E., Schmidt K.G. et al. Pearson marrowpancreas syndrome with worsening cardiac function caused by pleiotropic rearrangement of mitochondrial DNA Am J Med Genet 2002; 110: 57-61.

45. Sproule D.M., Kaufmann P. Mitochondrial encephalopathy, lactic acidosis, and strokelike episodes: basic concepts, clinical phenotype, and therapeutic management of MELAS syndrome. Ann N Y Acad Sci 2008; 1142: 133-158.

46. Kolb S.J., Costello F., Lee A.G. et.al. Distinguishing ischemic stroke from the stroke-like lesions of MELAS using apparent diffusion coefficient mapping. J Neurol Sci 2003; 216: 11-15.

47. Goto Y., Nonaka I., Horai S. A mutation in the tRNA Leu(UUR) gene associated with the MELAS subgroup of mitochondrial encephalomyopathies. Nature 1990; 348: 651-653.

48. Finsterer $J$. Genetic, pathogenetic, and phenotypic implications of the mitochondrial A3243G tRNALeu (UUR) mutation. Acta Neurol Scand 2007; 116: 1-14.

49. Finsterer J. MELAS in the heart. Int J Cardiol 2009; 137: 65-66.

50. Anan R., Nakagawa M., Miyata M. et al. Cardiac involvement in mitochondrial diseases. A study on 17 patients with documented mitochondrial DNA defects. Circulation 1995; 91: 955-961.

51. Sproule D.M., Kaufmann P., Engelstad K. et al. Wolff-Parkin-
son-White syndrome in patients with MELAS. Arch Neurol 2007; 64: 1625-1627.

52. Sato W., Tanaka M., Sugyama S. et al. Cardiomyopathy and angiopathy in patients with mithochondrial myopathy encephalopathy lactic acidosis and stroke like episodes. Amer Heart J 1994; 128: 4: 733-741.

53. Леонтьева И.В. Кардиомиопатии при первичной митохондриальной патологии. Лечащий врач 2002; 7-8: 58-66. (Leont'eva I.V. Cardiomyopathies at primary mitochondrial pathology. Lechashhij vrach 2002; 7-8: 58-66.)

54. Molnar M.J., Perenyi J., Siska E. et al. The typical MERRF (A8344G) mutation of the mitochondrial DNA associated with depressive mood disorders. J Neurol 2009; 256: 264-265.

55. Ozava T. Mitochondrial cardiomyopathy. Herz 1994; 19: 2: $105-118$.

56. Wahbi K., Larue S., Jardel C. et al. Cardiac involvement is frequentin patients with the m.8344A $>\mathrm{G}$ mutation of mitochondrial DNA. Neurology 2010; 74: 674-677.

57. Сухоруков В.C. Очерки митохондриальной патологии. М: Медпрактика-M, 2011; 288. (Sukhorukov V.S. Mitochondrial pathology outlines. Moscow: Medpraktika 2011; 288.)

58. López-Gallardo E., Solano A., Herrero-Martín M.D. et al. NARP syndrome in a patient harbouring an insertion in the MT-ATP6 gene that results in a truncated protein. J Med Genet 2009; 46: 64-67.

59. Bugiani M., Invernizzi F., Alberio S. et al. Clinical and molecular findings in children with complex I deficiency. Biochim Biophys Acta 2004; 1659: 136-147.

60. Piao Y.S., Tang G.C., Yang H. et al. Clinico-neuropathological study of a Chinese case of familiar adult Leigh syndrome. Neuropathol 2006; 26: 218-221.

61. Levitas A., Muhammad E., Harel G. et al. Familial neonatal isolated cardiomyopathy caused by a mutation in the flavoprotein subunit of succinate dehydrogenase. Eur J Hum Genet 2010; 18: 1160-1165.

62. Николаева Е.А., Яблонская М.И., Харабадзе М.Н. и др. Эффективность комплексной терапии при разных формах митохондриальных заболеваний у детей. Рос вестн перинатол и педиатр 2009; 6: 26-30. (Nikolaeva E.A., Yablonskaya M.I., Kharabadze M.N. et al. Efficiency of complex therapy at different forms of mitochondrial diseases at children. Ros vestn perinatol i pediatr 2009; 6: 26-30.)

63. Arakawa K., Kudo T., Ikawa M. et al. Abnormal myocardial energyproduction state in mitochondrial cardiomyopathy and acute response to L-arginine infusion: $\mathrm{C}-11$ acetate kinetics revealed by positron emission tomography. Circ J 2010; 74: 2702.

64. Finsterer J., Stöllberger C., Gelpi E. Successful heart failure therapy in mitochondrial disorder with noncompaction cardiomyopathy Int J Cardiovasc Imaging 2006; 22: 393-398.

65. Fosslien E. Mitochondrial medicine-cardiomyopathy caused by defective oxidative phosphorylation. Ann Clin Lab Sci 2003; 33: 371-395.

66. Santorelli F.M., Gagliardi M.G., Dionisi-Vici C. et al. Hypertrophic cardiomyopathy and mtDNA depletion. Successful treatment with heart transplantation. Neuromuscul Disord 2002; 12: $56-59$. 